\title{
MODELLING AND SIMULATION OF COMPLEX PNEUMATIC CONTROL VALVE FOR TRAIN BRAKING SYSTEMS
}

\author{
WU MENG-LING, ZHU LU \& TIAN CHUN \\ Institute of Railway and Urban Mass Transit, Tongji University, Shanghai, China
}

\begin{abstract}
Aimed at discrete character of complex pneumatic control valve, the 120 emergency valve was taken as an example. Under the theory of power bond graph and model approximation and introduction of controllable node and virtual element, the mathematic model of 120 emergency valve was built with uniform causality in different working modes. The created bond graph was utilized to research the effects of two structural parameters (aperture size of hole III and gap between piston rod and push rod) on stability and emergency sensitivity. Analysis results show that when the diameter is designed as $2.5 \mathrm{~mm}$, the selection range of the gap will be $3-3.5 \mathrm{~mm}$; when the gap is designed as $3 \mathrm{~mm}$, the diameter will be $2.5-2.7 \mathrm{~mm}$. The proposed method may be commonly applied to modelling and analysis of other complex pneumatic control valve.
\end{abstract}

Keywords: 120 emergency valve, bond graph, pneumatic control valve, railway, simulation model

\section{INTRODUCTION}

As a key component of the train braking system, the structural optimization and performance analysis of pneumatic control valve is an important guarantee for the safe operation of the train. At present, the pneumatic control valve on the freight train can basically meet the braking requirements, but its failure rate is still high. Therefore, it is urgent to study the characteristics of the pneumatic control valve.

Pneumatic control valve is a complex component with energy conversion between various energy domains. Through controlling the movement of the spool, the working modes can be changed, which means it belongs to the typical hybrid dynamic system with transient discrete characteristics. Therefore, how to establish reasonable model of pneumatic control valve is the focus of this article when considering multi-energy domain coupling and discrete characteristics.

At present, the research methods of air control valve are based on the airflow theory [1-6], equivalent principle [7-9] and power bond graph. The method based on the theory of airflow is limited to the description of gas transient flow, and the dynamics of other energy domains can only be obtained through kinetic equations that contain intermediate variables of each relevant subsystem. This process is quite cumbersome and fallible [10]. The method based on equivalent principle can simplify the modelling process without paying attention to the dynamics of gas flow, but there is no one-to-one relationship between established model and physical system which can reduce the operability of the functional analysis.

However, the method based on the power bond graph can be used to reflect the conservation process of different domains in a simple and consistent way. The modelling process is simple and the model is readable with lots of useful information [11]. Now the mature bondgraph theory has been widely used in many fields, such as complex mechanical system [12], fault detection $[13,14]$, automatic control [15] and so on.

In order to reflect the discrete characteristics of the gas control valve, the MA (model approximation) method was introduced on the basis of the power bond graph, and the controllable node and the virtual element were used to creatively propose the modelling method 
of 120 emergency valve with mode switching. In Matlab/Simulink, the simulation of the bond-graph model was carried out. By analysing the stability and emergency sensitivity of the emergency valve, aperture size of hole III and gap between piston rod and push rod were selected. The simulation results show that this method is not only a powerful analytical tool to study the working characteristics of air control valves but also provides a theoretical basis for the design improvement of air control valves.

\section{WORKING PRINCIPLE OF 120 EMERGENCY VALVE}

The 120 emergency valve is an important component of the braking system of freight train, which is used to produce extra exhaust to accelerate pressure reduction speed of train pipe during emergency brake. The internal structure of the emergency valve is shown in Fig. 1.

As shown in Fig. 1, the movement of the piston rod, controlled by the pressure of the compressed gas, can change the working modes, that is, when releasing, emergency chamber inflates and the piston rod is close to the emergency valve cover to keep static; when emergency braking, the snort valve is open and the maximum displacement of the piston rod is $>4 \mathrm{~mm}$; when service braking, the maximum displacement is $\leq 4 \mathrm{~mm}$ while the snort valve is closed.

In order to simplify the model, the following assumptions are made:

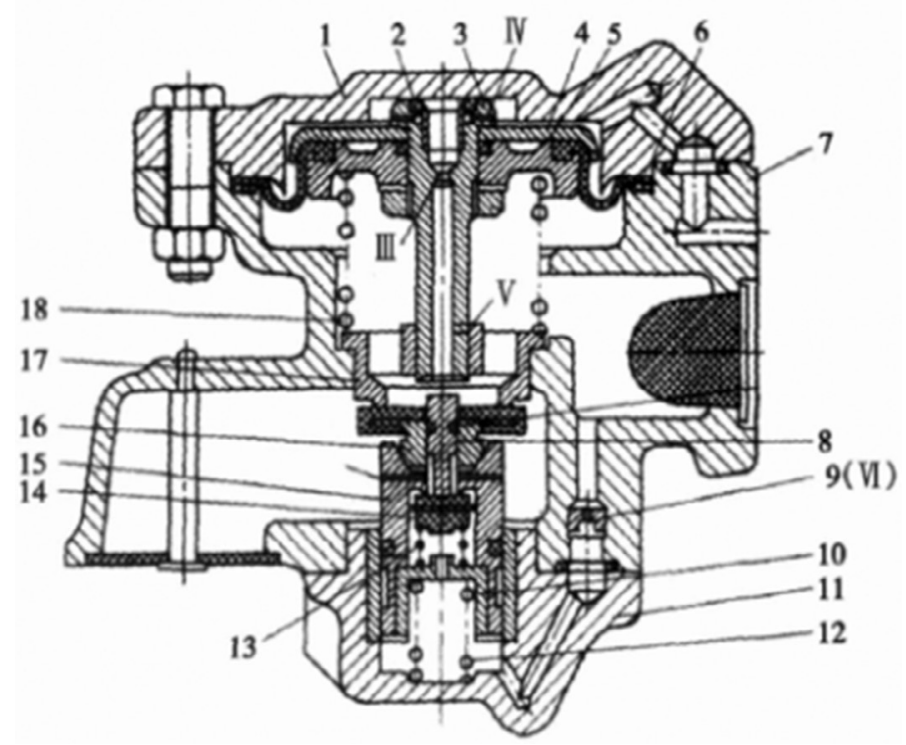

Figure 1: Schematic diagram of emergency part of 120 Valve

1, bonnet; 2 , gasket; 3 , piston rod; 4 , pressing plate; 5 , piston body; 6 , template; 7 , valve body; 8 , push rod of pilot valve; 9 , hole VI; 10 , spring seat; 11 , bonnet of snort valve; 12 , spring of snort valve;

13 , spring of pilot valve; 14 , sandwich valve of pilot valve; 15 , valve rod of snort valve;

16, component of snort valve; 17 , valve seat of snort valve; 18 , stability spring; III, axial centre hole of piston rod; IV, upper radial hole of piston rod; V, lower radial hole of piston rod. 
1) Gas flow is the isentropic process, without heat exchange and friction heat.

2) The brake cylinder is considered as a constant volume.

3) Leakage of the valve is ignored.

4) Sliding friction in the mechanical system is ignored.

\section{MODELLING OF 120 EMERGENCY VALVE}

\subsection{Bond-graph model of 120 emergency valve}

Combined with the internal structure of the 120 emergency valve and the interaction between the components, the properties of elements are distinguished, as shown in Table 1.

It is shown in Fig. 1 that $\mathrm{V}$ is consistent with the on-off state of the radial hole of the pilot valve, and the state of the snort valve is directly related to its movement. Therefore, in order to reflect the discrete nature, the controllable nodes are introduced into the bond-graph theory [16]. With the change of the controllable node, the causal relationship of the bond-graph element connected with the controllable node will also change accordingly, which will increase the uncertainty of the model. Therefore, the virtual elements 'MR-' are introduced based on MA method to simulate the on-off state of the corresponding holes. The bond-graph model with uniform causal relationship under different working modes can be received, as shown in Fig. 2. In this figure, the controllable nodes $I_{4}, I_{5}$ and $I_{6}$ describe the movement state of the piston rod, the pilot valve and the snort valve, respectively, and on-off indicates the connection state of the corresponding node.

In Fig. 2, $P$ and $Q$ are pressure and mass flow of brake pipe; $F_{j}, F_{x}$ and $F_{f}$ are the pre-tightening force of stability spring, spring of pilot valve and snort valve; $M R_{j}, M R_{x}$ and $M R_{f}$ represent $\mathrm{V}$, the radial hole of the pilot valve and the orifice of the snort valve, respectively; $A_{j 1}$ and $A_{j 2}$ are the upper and lower sectional areas of piston, while $A_{f 1}$ and $A_{f 2}$ are the sectional areas of snort valve.

Table 1: Parameters of emergency part in bond graph.

\begin{tabular}{lll}
\hline Name & Property & Parameters \\
\hline Stability spring chamber & Capacitive & $C_{1}$ \\
Spring chamber of snort valve & Capacitive & $C_{2}$ \\
Emergency valve chamber & Capacitive & $C_{j 1}$ \\
Stability spring & Capacitive & $C_{j 2}$ \\
Spring of pilot valve & Capacitive & $C_{x}$ \\
Spring of snort valve & Capacitive & $C_{f}$ \\
Filter & Resistive & $R_{1}$ \\
VI & Resistive & $R_{2}$ \\
Mass of emergency piston & Inertial & $I_{j}$ \\
Mass of pilot valve & Inertial & $I_{x}$ \\
Mass of snort valve & Inertial & $I_{f}$ \\
\hline
\end{tabular}




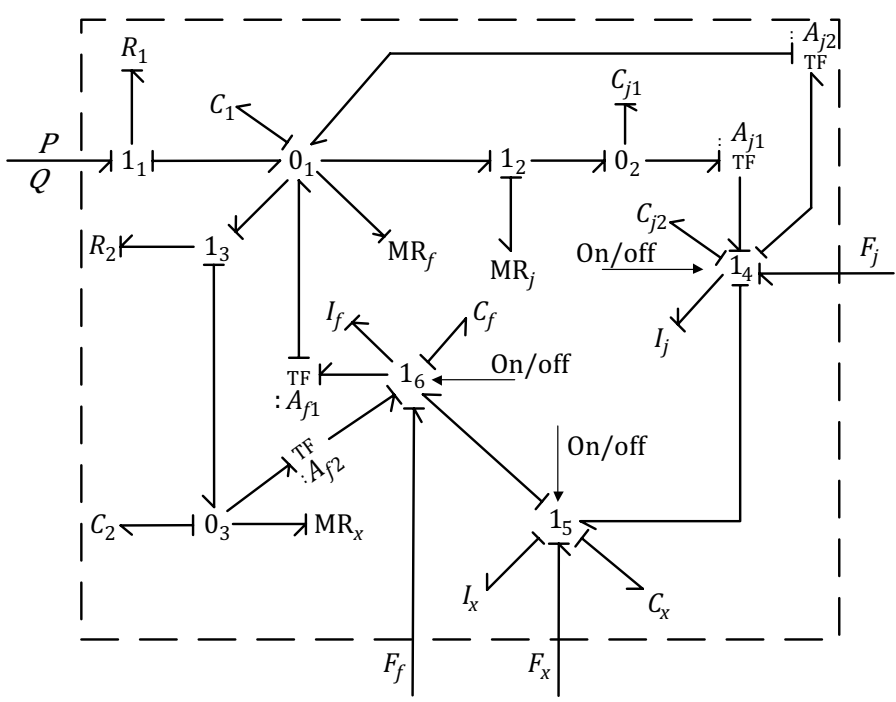

Figure 2: Bond-graph model of emergency part.

The states of controllable nodes $I_{4}, I_{5}$ and $I_{6}$ can be described by binary variate $\partial_{i}$, that is, when the node is active, $\partial_{i}=1$; when static, $\partial_{i}=0$. Therefore, the velocity of component is given as

$$
v_{i}=\left\{\begin{array}{l}
0, \partial_{i}=0 \\
\frac{\int \sum F_{i} d t}{m_{i}}, \partial_{i}=0
\end{array}\right.
$$

where $\sum F_{i}$ is the resultant force acting upon component $i, m_{i}$ is the mass of $i$.

Accordingly, the on-off states of $M R_{j}, M R_{x}$ and $M R_{f}$ can be represented by the resistance coefficient $r_{i}$. Combined with the states of controllable nodes and characteristics of resistive elements, $r_{i}$ can be expressed as

$$
r_{i}=\left\{\begin{array}{cll}
\frac{\left(P_{u}-P_{d}\right) \sqrt{2 R T}}{A_{e} P_{u}} & 0 \leq \frac{P_{d}}{P_{u}} \leq 0.528 & \\
\frac{\sqrt{R T\left(P_{u}-P_{d}\right)}}{A_{e i} \sqrt{2 P_{d}}} & 0.528<\frac{P_{d}}{P_{u}}<1 & \\
& & \partial_{i}=1 \\
& \infty & \partial_{i}=0
\end{array}\right.
$$

where $A_{\text {ei }}$ is the sectional area of component $i ; P_{u}$ and $P_{d}$ are the pressures of upstream and downstream, respectively; $R$ is the gas constant for air; $T$ is the local temperature.

To define the controllable nodes, the relative variates and control conditions are shown in Table 2 . 
Table 2: Switch variable of 120 emergency valve.

\begin{tabular}{lllll}
\hline Name & Controllable node & Boolean variable & Bond variable & Control condition \\
\hline Piston & $1_{4}$ & $a$ & $a \dot{q}_{j 2}$ & When releasing, $a=1$ \\
& & & & When braking, $a=0$ \\
Pilot valve & $1_{5}$ & $b$ & $b \dot{q}_{x}$ & $\begin{array}{l}q_{j 2} \geq 3 \mathrm{~mm}, b=1 \\
\end{array}$ \\
& & & & $q_{j 2}<3 \mathrm{~mm}, b=0$ \\
Snort valve & $1_{6}$ & $c$ & $c \dot{q}_{f}$ & $\begin{array}{l}q_{j 2} \leq 4 \mathrm{~mm}, c=1 \\
\end{array}$ \\
& & & $q_{j 2}>4 \mathrm{~mm}, c=0$
\end{tabular}

In Table 2, $a, b, c$ are Boolean variables with the value 1 or $0 ; \dot{q}_{j 2}, \dot{q}_{x}$ and $\dot{q}_{f}$ are displacements of stability spring and spring of pilot valve and snort valve.

\subsection{State equation of 120 emergency valve}

In Fig. 2, the conversion, storage and consumption process of the internal power flow of the emergency valve is described in the dashed box, and the energy exchanged between the emergency valve and other systems is shown in the outside of dashed box. Combined with the bond-graph model and the relevant theoretical knowledge, the state equation of the emergency valve can be obtained as

$$
\dot{X}_{J}=A_{j} X_{j}+B_{j} U_{j}
$$

where $X_{j}=\left[\begin{array}{lllllllll}q_{1} & q_{2} & q_{j 1} & q_{j 2} & q_{x} & q_{f} & p_{j 2} & p_{x} & p_{f}\end{array}\right]^{T}, U_{j}=\left[\begin{array}{llll}P & F_{j} & F_{x} & F_{f}\end{array}\right]^{T}$

$$
A=\left[\begin{array}{ccccccccc}
-\frac{1}{c_{1}}\left(\frac{1}{r_{1}}+\frac{1}{r_{2}}+\frac{1}{r_{j}}+\frac{1}{r_{f}}\right) & -\frac{1}{c_{2} r_{2}} & \frac{1}{r_{j}} & 0 & 0 & 0 & a A_{j 2} & 0 & -c A_{f 1} \\
-\frac{1}{c_{1} r_{2}} & \frac{1}{c_{1}}\left(\frac{1}{r_{2}}+\frac{1}{r_{x}}\right) & 0 & 0 & 0 & 0 & 0 & 0 & c A_{f 2} \\
\frac{1}{c_{1} r_{j}} & 0 & \frac{1}{c_{j} r_{j}} & 0 & 0 & 0 & -a A_{j 1} & 0 & 0 \\
0 & 0 & 0 & 0 & 0 & 0 & \frac{1}{a i_{j}+b i_{x}+c i_{f}} & 0 & 0 \\
0 & 0 & 0 & 0 & 0 & 0 & 0 & \frac{1}{a i_{j}+b i_{x}+c i_{f}} & 0 \\
\frac{c A_{f 1}-a A_{j 2}}{c_{1}} & -\frac{c A_{f 2}}{c_{2}} & \frac{a A_{j 1}}{c_{j 1}} & -\frac{a}{c_{j 2}} & -\frac{b}{c_{x}} & -\frac{c}{c_{f}} & 0 & 0 & \frac{1}{a i_{j}+b i_{x}+c i_{f}} \\
\frac{c A_{f 1}-b A_{j 2}}{c_{1}} & -\frac{c A_{f 2}}{c_{2}} & \frac{b A_{j 1}}{c_{j 1}} & -\frac{b}{c_{j 2}} & -\frac{b}{c_{x}} & -\frac{c}{c_{f}} & 0 & 0 & 0 \\
\frac{c A_{f 1}-c A_{j 2}}{c_{1}} & -\frac{c A_{f 2}}{c_{2}} & \frac{c A_{j 1}}{c_{j 1}} & -\frac{c}{c_{j 2}} & -\frac{c}{c_{x}} & -\frac{c}{c_{f}} & 0 & 0 & 0
\end{array}\right]
$$




$$
B=\left[\begin{array}{cccc}
\frac{1}{r_{1}} & 0 & 0 & 0 \\
0 & 0 & 0 & 0 \\
0 & 0 & 0 & 0 \\
0 & 0 & 0 & 0 \\
0 & 0 & 0 & 0 \\
0 & 0 & 0 & 0 \\
0 & -a & -b & -c \\
0 & -b & -b & -c \\
0 & -c & -c & -c
\end{array}\right]
$$

where $x_{j}$ is the state variable matrix of emergency valve, $U_{j}$ is the external input matrix, $p_{m}$ is the momentum of the component $m, q_{m}$ is the displacement, $c_{m}$ is the capacity and $r_{m}$ is the resistance coefficient. The main components are the stability spring chamber $(m=1)$, the spring chamber of snort valve $(m=2)$, emergency chamber $(m=j 1)$, stability spring $(m=j 2)$, pilot valve $(m=x)$ and snort valve $(m=f)$.

The state equation of the emergency valve can truly reflect the interaction between the compressed gas and the mechanical components in the pneumatic system, that is, when the displacement of piston is $<3 \mathrm{~mm}$, the net force on the piston is subjected to

$$
\dot{p}_{j 2}=\left(\frac{q_{j 1}}{c_{j 1}} A_{j 1}-\frac{q_{1}}{c_{1}} A_{j 2}\right)-\frac{q_{j 2}}{c_{j 2}}-F_{j}
$$

where $p_{j 2}$ shows the change rate of the piston momentum; the right first term represents the net force on piston in which $\frac{q_{j 1}}{c_{j 1}}$ is the pressure of emergency chamber and $\frac{q_{1}}{c_{1}}$ is the pressure of stability spring chamber; $\frac{q_{j 2}}{c_{j 2}}$ and $F_{j}$ are the spring force and pre-tightening force of stability force. Therefore, the gas flow of emergency chamber is given as

$$
\dot{q}_{j 1}=\frac{1}{r_{j}}\left(\frac{q_{1}}{c_{1}}-\frac{q_{j 1}}{c_{j 1}}\right)-A_{j 1} \frac{p_{j}}{i_{j}}
$$

where $q_{j 2}$ is the change rate of gas quality in emergency chamber; the right first term is the mass flow into the emergency chamber per unit time; the right second term is the consumed energy for working against resistance. It can be seen that the dynamic characteristics of the gas in the chamber are related not only to the flow rate of the inlet but also to the kinematic momentum of the piston. Therefore, the use of bond-graph theory can truly describe the gas dynamics in the chamber, which also shows that it has a unique advantage in dealing with multi-domain complex system.

\section{SIMULATION RESEARCH OF 120 EMERGENCY VALVE}

\subsection{Validation of simulation mode}

The simulation model of 120 emergency valve is built in Matlab/Simulink, and the key parameters are shown in Table 3. In order to verify the correctness of the bond-graph model, the initial 
Table 3: Key parameters of 120 emergency valve.

\begin{tabular}{|c|c|c|c|}
\hline Component & Part & Para & eters \\
\hline \multirow{10}{*}{ Emergency valve } & Piston body & Diameter & $76 \mathrm{~mm}$ \\
\hline & \multirow{2}{*}{ Pilot valve } & Diameter & $16 \mathrm{~mm}$ \\
\hline & & Spring rate & $1,980 \mathrm{~N} / \mathrm{m}$ \\
\hline & \multirow{2}{*}{ Snort valve } & Diameter & $45 \mathrm{~mm}$ \\
\hline & & Spring rate & $4,480 \mathrm{~N} / \mathrm{m}$ \\
\hline & Stability spring & Spring rate & 390 N/m \\
\hline & \multirow{4}{*}{ Hole } & III & $2.5 \mathrm{~mm}$ \\
\hline & & IV & $0.5 \mathrm{~mm}$ \\
\hline & & $\mathrm{V}$ & $1.1 \mathrm{~mm}$ \\
\hline & & VI & $1 \mathrm{~mm}$ \\
\hline
\end{tabular}

inflation and emergency brake were simulated and the emergency sensitivity and stability were analysed. The pressure curves of the train pipe and emergency chamber are shown in Figs 3-5.

The standard requirements of emergency valve on the test bed are as follows: emergency chamber inflation (from 0 to $480 \mathrm{kPa}$ ) time is $40-55 \mathrm{~s}$ and exhaust (from 500 to $40 \mathrm{kPa}$ ) time is $14-18 \mathrm{~s}$. When the pressure of brake pipe is dropped from 500 to $40 \mathrm{kPa}$, if it requires $\leq 7 \mathrm{~s}$, then the emergency brake can be triggered; if it requires $>8 \mathrm{~s}$, the train does not have an emergency brake. During emergency brake, the extra exhaust will start when the pressure reduction of brake pipe is $\leq 100 \mathrm{kPa}$ and the time from the beginning of the extra exhaust to the pressure of brake pipe down to $40 \mathrm{kPa}$ is $\leq 1.5 \mathrm{~s}$.

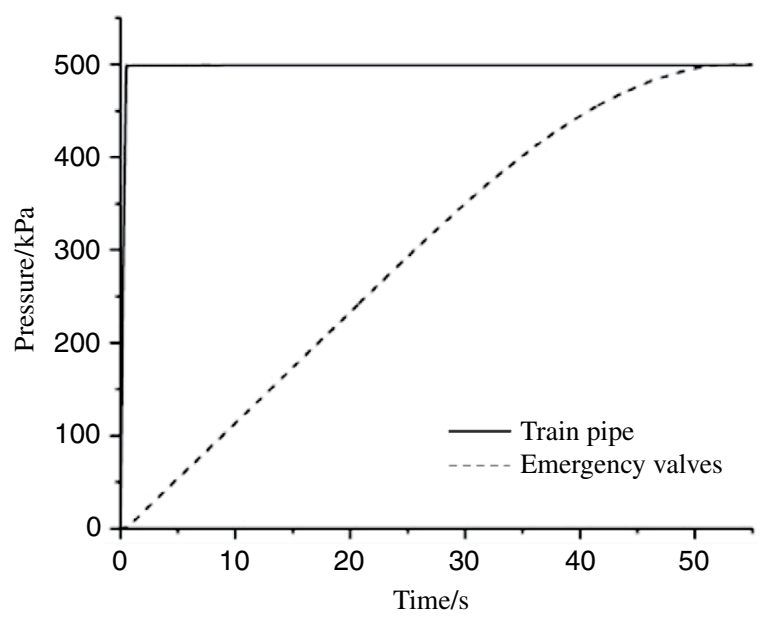

Figure 3: Pressure curve in initial charging. 


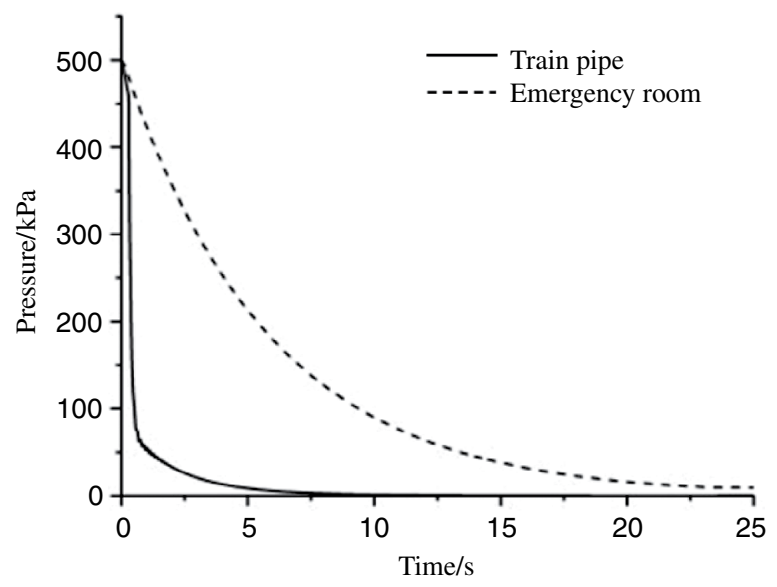

Figure 4: Pressure curve in emergency brake.

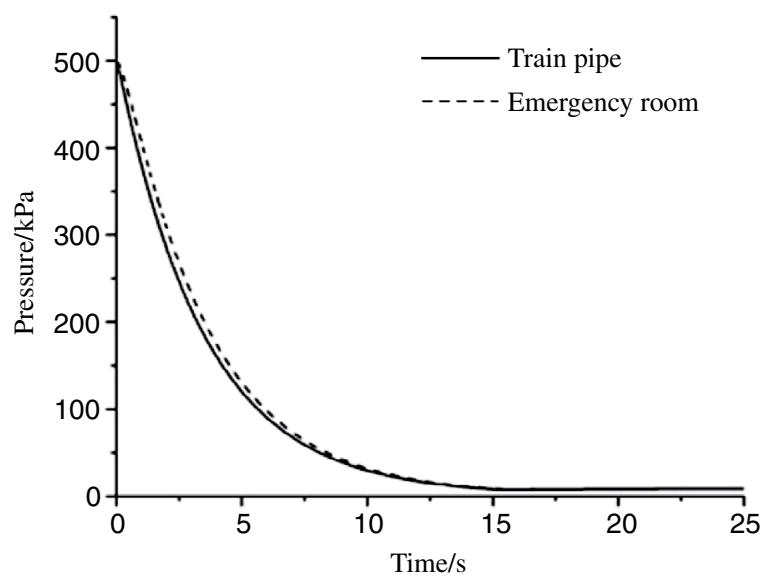

Figure 5: Pressure curve in emergency brake.

As the emergency chamber is small, in the releasing phase, the pressure of brake pipe is considered as constant pressure source, in which the value is $500 \mathrm{kPa}$; in the braking phase, in order to simulate the time of pressure drop of brake pipe (from $500 \mathrm{kPa}$ down to $40 \mathrm{kPa}$ ), the brake pipe is considered as a fixed chamber and the initial gas pressure is $500 \mathrm{kPa}$. During braking, the brake pipe begins to exhaust, whose mathematical model of the brake pipe is given as

$$
\begin{aligned}
\dot{q} & =\frac{A P_{0}}{\sqrt{2 R T}} \\
P_{0} & =\frac{q}{c}
\end{aligned}
$$

where $\dot{q}$ is the change rate of mass flow in the pipe, $P_{0}$ is the transient pressure, $c$ is the capacity and $A$ is the sectional area of exhaust hole in the pipe. Therefore, the mathematical model can be used to simulate the external environment used to analyse the emergency sensitivity and stability. 
As shown in Fig. 3, the initial inflation time of emergency chamber (up to $480 \mathrm{kPa}$ ) is $45.8 \mathrm{~s}$. During the emergency brake (shown in Fig. 4), the emergency valve began to exhaust when the pressure reduction of brake pipe is $42.1 \mathrm{kPa}$; the time from the beginning of the extra exhaust to the pressure of brake pipe down to $40 \mathrm{kPa}$ is $1.25 \mathrm{~s}$, while the time from the start of the extra exhaust to the pressure of emergency chamber down to $40 \mathrm{kPa}$ is $14.7 \mathrm{~s}$. During service brake, the time is $8.9 \mathrm{~s}$ when the pressure of brake pipe drops to $40 \mathrm{kPa}$, in which the emergency brake isn't prompted (shown in Fig. 5).

Compared with the simulation results and the experimental data, the simulation curves meet the requirements of the test standard, which can verify the rationality and effectiveness of the bond-graph model of 120 emergency valve.

\subsection{Analysis of braking characteristics}

\subsubsection{The choose of structural parameters}

Both the emergency sensitivity and stability of 120 emergency valve are important indicators to describe its working performance. From the working principle of the 120 emergency valve, it can be seen that the emergency sensitivity and stability are directly reflected by the displacement of the piston rod, which is determined by the stability spring, the spring of pilot valve, the spring of snort valve, the aperture size of hole III and other structural parameters.

There are some rules about the overhaul of main pipe and the pipe between main pipe and cutout cock in 'The railway depot repair process', but don't make any demands on the pipe between cutout cock and 120 emergency valve. The air-tight test of the 120 emergency valve will only be done during shop repair, so hole III is easy to be blocked. Compared with other two springs, the stability spring is used frequently which leads to ageing easily. The ageing of the stability spring finally reflects the gap between piston rod and push rod that is not easy to control in the manufacturing process. Therefore, the impacts of the hole III and the gap on emergency sensitivity and stability were studied in this article based on the bond-graph model of 120 emergency valve.

\subsubsection{Stability analysis}

In the 120 emergency valve, the standard size of hole III is $2.5 \mathrm{~mm}$, and the aperture will be modified in the simulation. To avoid triggering an emergency brake, it is assumed that the gap is infinite. Figure 6 shows the displacement of the piston rod with the change of the diameter of hole III during the service brake. It can be seen that the maximum displacement is gradually smaller and the growth rate is decreasing with the increase of the diameter of hole III.

When the diameter is $2.0,2.5$ and $3.0 \mathrm{~mm}$, respectively, the maximum displacement is $6.483,2.852$ and $1.25 \mathrm{~mm}$ accordingly. In fact, the maximum displacement is directly linked to the stability of the 120 emergency valve. The stability can be ensured when the gap is not less than the maximum displacement. As shown in Fig. 7, if the point defined by the gap and the diameter falls into the right side of the critical line (zone B), it cannot trigger undesirable emergency brake during service brake. When the diameter is $<2.5 \mathrm{~mm}$ and the gap is $<3 \mathrm{~mm}$, an unexpected emergency brake will be easily prompted.

\subsubsection{Emergency sensitivity analysis}

During the emergency brake, change the gap and the diameter to observe the emergency sensitivity, as shown in Table 4. In this table, ' $/$ ' respects the trigger of emergency brake unsuccessfully, '-' describes the appearance of unexpected emergency brake. 


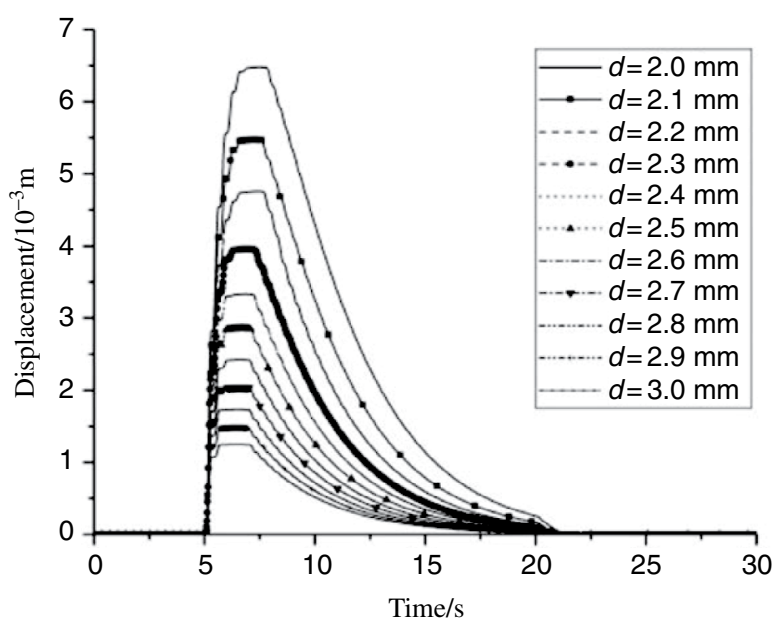

Figure 6: Displacement of piston with different III aperture sizes.

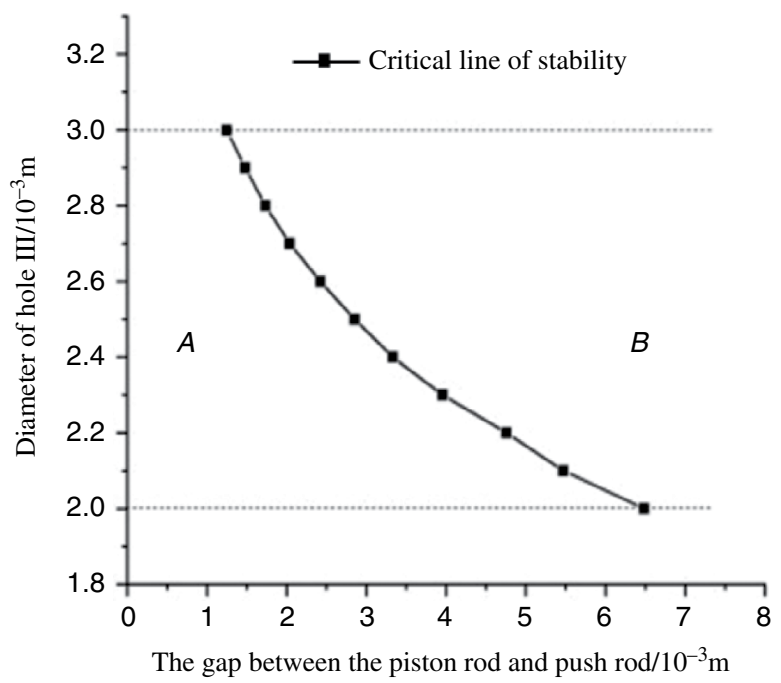

Figure 7: Critical line of stability.

The emergency sensitivity is increasing as the gap and the diameter increase. The standard requirement of emergency valve on the test bed [17] is that the emergency brake starts if the pressure reduction of brake pipe is $\leq 100 \mathrm{kPa}$. According to the experience, when the emergency sensitivity is less than $40 \mathrm{kPa}$, an unexpected emergency will be easily prompted. Therefore, the appropriate range of emergency sensitivity is $40-100 \mathrm{kPa}$. It can be judged from Table 4 that when the diameter is $>3 \mathrm{~mm}$ or the gap is $>5 \mathrm{~mm}$, it fails to trigger emergency brake. 


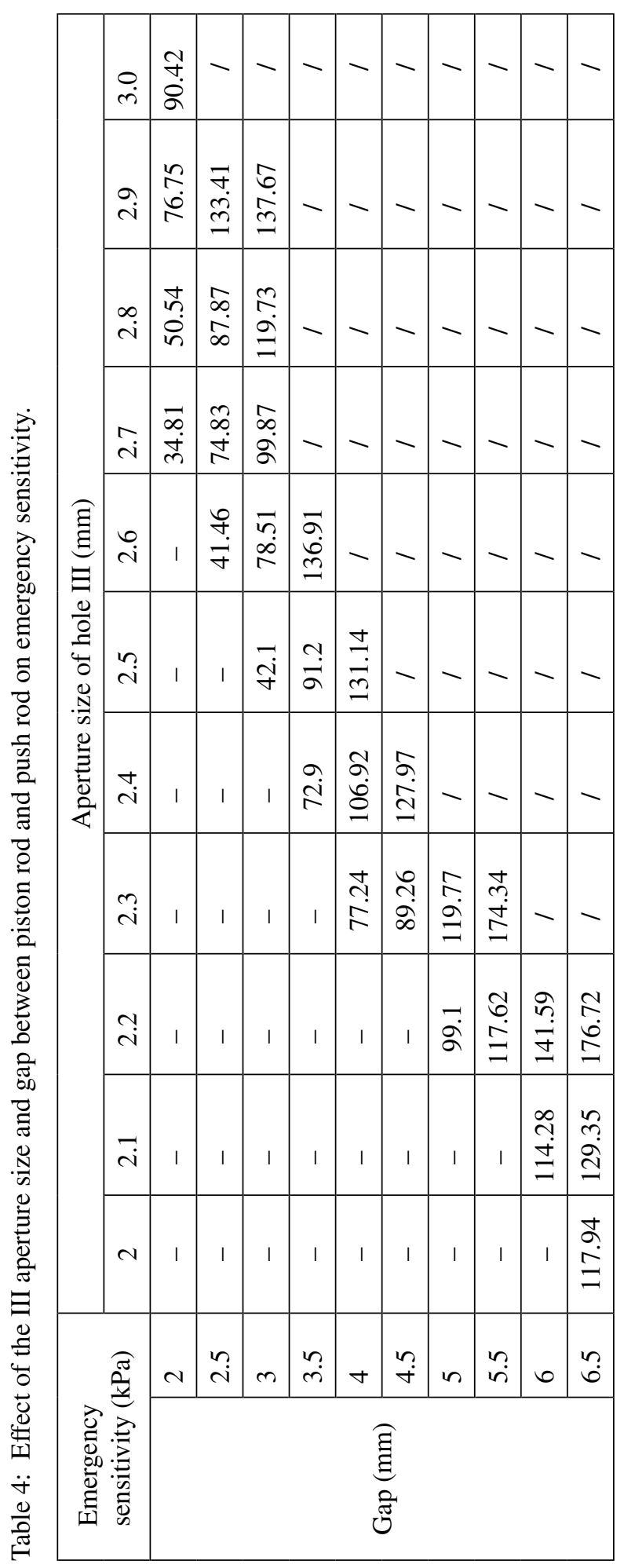


In general, the standard size of the gap and the diameter is 3 and $2.5 \mathrm{~mm}$, respectively. The effective flow area of hole III can be smaller due to impurities in the air. Therefore, in order to improve the reliability and stability of the 120 emergency valve, taking the stability and emergency sensitivity into account, when the diameter of III is $2.5 \mathrm{~mm}$, the range of gap should be $3-3.5 \mathrm{~mm}$; when the gap is $3 \mathrm{~mm}$, the diameter of III should be $2.5-2.7 \mathrm{~mm}$.

\section{CONCLUSION}

In this article, the MA method based on power bond graph was introduced, combined with the controllable nodes and virtual elements, and the bond-graph model of 120 emergency valve that can reflect the multi-energy domains coupling and discrete characteristics was established to study the influence on emergency sensitivity and the stability caused by the gap between the piston rod and push rod, aperture size of hole III.

(1) Based on the power bond graph, the controllable nodes were introduced to reflect the discrete characteristics of the gas control valve and realize the conversion of working modes in the same bond-graph model. Using the 120 emergency valve, described in this article, the releasing, service braking and emergency braking modes can be switched with the introduction of three controllable nodes.

(2) The causal relationship of the bound graph will be changed with the change of the controllable nodes' state. To avoid this situation, the bond-graph model with unified causal relationship in different working modes was obtained with the introduction of virtual elements by the MA method. In this article, the virtual element 'MR-' was introduced to simulate the on-off state of lower radial hole of piston rod, the radial hole of the pilot valve and the orifice of the snort valve, respectively, and then a bond-graph model with uniform causal relationship was established.

(3) The modelling method proposed in this article is suitable for the analysis of the working characteristics of air control valves. The influences on emergency sensitivity and stability caused by structural parameters were studied by the application of the bond-graph model of 120 emergency valve. When the aperture size of hole III is $<2.5 \mathrm{~mm}$ and the gap is $<3 \mathrm{~mm}$, it is easy to trigger an unexpected emergency brake; when the diameter is $>3 \mathrm{~mm}$ or the gap is $>5 \mathrm{~mm}$, it is easy to lead to emergency braking failure; when the diameter is $2.5 \mathrm{~mm}$, the gap should be $3-3.5 \mathrm{~mm}$; when the gap is $3 \mathrm{~mm}$, the diameter should be $2.5-2.7 \mathrm{~mm}$.

\section{REFERENCES}

[1] Wei, W. \& Li, H., Simulation of 120 Vehicle Distribute Valve and its test rig - Main valve model and results [J]. Journal of Dalian Railway Institute, 21(2), pp. 18-24, 2000. DOI: 10.1128/MCB.13.8.4513.

[2] Wei, W., Liu, T. \& Zhang, J., The simulation model of KZ1 Control Valve and the simulation study on train braking performance [J]. China Railway Science, 2010(01), pp. 105-110, 2010. DOI: 10.1016/S0045-7825(98)80008-X.

[3] Piechowiak, T., Pneumatic train brake simulation method [J]. Vehicle System Dynamics, 47(12), pp. 1473-1492, 2009. DOI: 10.1080/00423110802600946.

[4] Zhao, Y. \& Wei, W., The effect of the 120 valve aperture to the brake system performance [J]. Journal of Railway Science and Engineering, 9(1), pp. 68-73, 2012. DOI: 10.3969/j.issn.1672-7029.2012.01.013. 
[5] Murtaza, M.A. \& Garg, S.B.L., Brake modelling in train simulation studies [J]. Proceedings of the Institution of Mechanical Engineers, Part F: Journal of Rail and Rapid Transit, 203(2), pp. 87-95, 1989. DOI: 10.1016/0020-7403(70)90042-1.

[6] Murtaza, M.A. \& Garg, S.B.L., Transients during a railway air brake release demand [J]. Proceedings of the Institution of Mechanical Engineers, Part F: Journal of Rail and Rapid Transit, 204(1), pp. 31-38, 1990. DOI: 10.1016/0020-7403(70)90042-1.

[7] Wu, Z., Ren, L., Pei, Y., et al., Simulation of relay-valve of metro braking system performance [J]. Urban Mass Transit, 14(9), pp. 52-57, 2011. DOI: 10.3969/j.issn.1007869X.2011.09.013.

[8] Yang, C., Ni, W., Jiang, D., et al., Modeling and simulation analysis of 120 emergency valve using AMESim [J]. Railway Locomotive, 29(6), pp. 37-39, 2009. DOI: 10.3969/j. issn.1008-7842.2009.06.012.

[9] Pugi, L., Palazzolo, A. \& Fioravanti, D., Simulation of railway brake plants: An application to SAADKMS freight wagons. Proceedings of the Institution of Mechanical Engineers, Part F: Journal of Rail and Rapid Transit, 222(4), pp. 321-329, 2008. DOI: 10.1243/0954409041319632.

[10] Guo, F., Li, Y., Song, Z. \& Zhang, L., Screw bond graph in the application of the parallel mechanism dynamics modelling [J]. Journal of Mechanical Engineering, 51(23), pp. 12-19, 2015. DOI: 10.3901/JME.2015.23.012.

[11] Yong, Y., Cong, H., Zhang, L., et al., Summarization of fault diagnosis method of dynamic system based on bond graphs [J]. Journal of Academy of Armored Force Engineering, 29(5), pp. 77-82, 2015. DOI: 10.3969/j.issn.1672-1497.2015.05.016.

[12] Saeed, B. \& Amir, K., Causality in vector bond graphs and its application to modeling of multi-body dynamic systems [J]. Simulation Modelling Practice and Theory, 14(3), pp. 279-295, 2006. DOI: 10.1016/j.simpat.2005.06.001.

[13] Borutzky, W., Bond graph model-based fault detection using residual sinks [J]. Journal of Systems and Control Engineering, 223(3), pp. 337-352, 2009. DOI: 10.1243/09544054JEM693.

[14] Niu, G. \& Zhao, Y., Bond graph model fault detection and isolation for locomotive brake [J]. Journal of Tongji University (Natural Science), 43(6), pp. 894-899, 2015. DOI: 10.11908/j.issn.0253-374x.2015.06.014.

[15] Marquis, F.W., Mouhib, O., Chereji, B., et al., Bond graph formulation of an optimal control problem for linear time invariant systems [J]. Journal of the Franklin Institute, 345(4), pp. 349-373, 2008. DOI: 10.1016/j.jfranklin.2007.10.005.

[16] Mosterman, P., Biswas, G., A theory of discontinuities in physical system models. Journal of the Franklin Institute, 335(3), pp. 401439, 1998. DOI: 10.1016/S00160032(96)00126-3.

[17] Ministry of Railways, Regulations for Freight Car Repair, China Railway Press, Beijing, 2012: 127-133. ISBN: 7-113-01334-1/U405. 